Angéla La ORCID iD: 0000-0002-7318-1661

\title{
A predictive dynamic yeast model based on component, energy, and electron carrier balances
}

\author{
Angéla $\mathrm{La}^{1,2}$, Huan $\mathrm{Du}^{2}$, Behnam Taidi ${ }^{1,2}$, Patrick Perré ${ }^{1,2, *}$, \\ ${ }^{1}$ LGPM, CentraleSupélec, Université Paris-Saclay, 8-10 rue Joliot-Curie, 91190 Gif- \\ sur-Yvette, France \\ ${ }^{2}$ LGPM, CentraleSupélec, Centre Européen de Biotechnologie et de Bioéconomie \\ (CEBB), 3 rue des Rouges Terres, 51110 Pomacle, France \\ *Corresponding author: patrick.perre@centralesupelec.fr (Patrick Perré)
}

\begin{abstract}
The present study describes a novel yeast model for the prediction of yeast fermentation. The proposed model considers the possible metabolic pathways of yeast. For each pathway, the time evolution of components, energy (ATP/ADP), and electron carriers ( $\mathrm{NAD}^{+} / \mathrm{NADH}$ ) are expressed with limitation factors for all quantities consumed by each respective pathway. In this manner, the model can predict partition of these pathways based on the growth conditions and their evolution over time. Several biological pathways and their stoichiometric coefficients are well-known from literature. It is important to note that most of kinetics parameters have no effect since actual kinetics are controlled by balance of limiting factors. The few remaining parameters were adjusted and compared with the literature when the dataset was available. The model fits our experimental data from yeast fermentation on glucose in non-aerated batch system. The predictive ability of the model and its capacity to represent the intensity of each pathway over time facilitate an improved understanding of interactions between the pathways. The key role of energy (ATP) and electron carrier $\left(\mathrm{NAD}^{+}\right)$to trigger the different metabolic pathways during yeast growth is highlighted, while involvement of mitochondrial respiration not being associated with the TCA cycle is also shown.
\end{abstract}

\section{Keywords}

energy balance, fermentation, TCA cycle, metabolic pathway, respiration

This article has been accepted for publication and undergone full peer review but has not been through the copyediting, typesetting, pagination and proofreading process, which may lead to differences between this version and the Version of Record. Please cite this article as doi: 10.1002/bit.27442.

This article is protected by copyright. All rights reserved. 


\section{Introduction}

The fermentation of organic substrates using yeast is one of the oldest and most popular metabolic processes used in biotechnological processes such as beer brewing, winemaking, and biofuel fermentation (Dashko et al., 2014). Saccharomyces cerevisiae is commonly used for its capacity to rapidly convert sugars to ethanol and carbon dioxide under both aerobic and anaerobic conditions (Hagman et al., 2014). Under aerobic conditions, respiration can occur with molecular oxygen as the final electron acceptor; however, $S$. cerevisiae also produces ethanol when the glucose concentration exceeds $0.10-0.15$ g. $\mathrm{l}^{-1}$ (Verduyn et al., 1984), thereby reducing the respiration process. This phenomenon is called the Crabtree effect (De Deken, 1966), and its emergence is likely due to the increased kinetics rate of ATP production through fermentation (Pfeiffer and Morley, 2014).

The fermentation activity in yeast depends on the biomass yield. Cramer et al. (2002) described ethanol production as completely proportional to the amount of biomass formed, as opposed to the growth-associated stoichiometric bioconversion of sugar to ethanol. Therefore, decreased yeast yield can lead to a reduction in fermentation activity rate (sluggish fermentation), or worse yet, to a premature cessation of ethanol production with more than $0.4 \%(\mathrm{w} / \mathrm{v})$ residual sugar remaining in the medium (stuck fermentation) (Bisson, 1999; Coleman et al., 2007). These phenomena are primarily caused by nitrogen and/or oxygen limitation and are often observed in the winemaking process, resulting in significant economic issues (Chaney et al., 2006). Nitrogen is an essential element in S. cerevisiae composition since it is mandatory for protein synthesis and represents 9\% (w/w) of yeast biomass (Verduyn et al., 1990a). Oxygen is required to regenerate $\mathrm{NAD}^{+}$used in the glycolytic pathway of biomass formation, closing the redox balance for the co-enzyme system $\mathrm{NAD}^{+} / \mathrm{NADH}$. The oxidation of cytosolic NADH into $\mathrm{NAD}^{+}$can occur through mitochondrial respiration with external NADH dehydrogenase (Bakker et al., 2001; Overkamp et al., 2000). Oxygen is also important for the synthesis of yeast membrane compounds (sterols and unsaturated fatty acids) (Sablayrolles, 1986), though this process could be neglected since the required amount is very weak at between 0.3 and $1.5 \mathrm{mg}_{\mathrm{O}_{2}} \cdot g_{D W}^{-1}$ (Rosenfeld et al., 2003). Consequently, fermentation activity is hinged on yeast biomass production, which is limited by nitrogen, organic carbon, and oxygen. The latter can be used as a strict respiration pathway (including the TCA cycle or Krebs cycle) to produce ATP and/or to close the $\mathrm{NAD}^{+} / \mathrm{NADH}$ system for the biomass glycolytic pathway. The pathway of ethanol production is also an ATP source for biomass formation. Most models have indirectly linked cell growth and ethanol production through a Monod-like function (Aiba et al., 1968; Bovee et al., 1984; Giovanelli et al., 1996; Holzberg et al., 1967; López and Secanell, 1992), with the exception of models from Cramer et al. (2002) and Coleman et al. (2007), in which ethanol production rate depends on the $S$. cerevisiae biomass yield as opposed to its growth. However, the models from Cramer et al. (2002) and Coleman et al. (2007) could be criticized since glucose is not integrated into the models as a limiting growth factor. In Liu et al. (2011), ethanol was associated with both $S$. cerevisiae growth and biomass concentration, though the model could also be partly disproven as yeast growth is not limited by nitrogen.

This article is protected by copyright. All rights reserved. 
Yeast models involving the ATP/ADP and NAD ${ }^{+} / \mathrm{NADH}$ systems have been developed in order to describe glycolytic oscillations over short periods of time (Hynne et al., 2001; Nielsen et al., 1998; Richter et al., 1975). Only fermentation is considered in these models, while the potential generation of ATP and NAD ${ }^{+}$through the respiratory chain is not considered. In the work of Rizzi et al. (1997), both fermentation and cellular respiration are considered; however, the model does not aim to predict $S$. cerevisiae growth. Notably, nitrogen is not included as a limiting growth factor, though it remains a key element of yeast biomass. The model focused on the prediction of changes in the metabolite concentration of steady-state continuous cultures following a glucose pulse over a short period of time (a time scale of seconds).

To our knowledge, no publication to date has described a yeast model that predicts yeast growth in a batch system by connecting the possible pathways of glucose utilization (ethanol, glycerol, biomass, and the TCA cycle) and the mitochondrial respiratory chain according to nutrients (nitrogen, carbohydrates, and oxygen), energy, and electron carrier balances. The aim and novelty of this work are to develop a yeast model that predicts the partition between several metabolic pathways based on nutrients, energy, and electron carrier balances (Figure 1). The model is then compared to the experimental results.

\section{Materials and methods}

\subsection{Yeast fermenter}

S. cerevisiae strain ID YLR249W was supplied by Life Technologies-University of California, San Francisco. Yeast fermentation was conducted in a non-aerated and closed 5l-bioreactor with temperature and $\mathrm{pH}$ adjusted at $25^{\circ} \mathrm{C}$ and 6.5 , respectively. Dissolved oxygen in the liquid phase was measured using an internal probe (La et al., 2019).

\subsection{Medium composition}

The culture medium was composed of glucose $\left(10 \mathrm{~g} . ~^{-1}\right)$, peptone $20\left(\mathrm{~g} . \mathrm{l}^{-1}\right)$, and mineral salts based on La et al. (2019). The nitrogen content in peptone was estimated from the free amino nitrogen (FAN) content. FAN in the medium was $5.4 \times 10^{-1} \mathrm{~g}$. $\mathrm{l}^{-1}$ so the concentration of nitrogen available to yeast was $6.4 \times 10^{-2} \mathrm{~g}$. $\mathrm{l}^{-1}$, by assuming that the average molar mass of an amino acid is 118.9 g. mole ${ }^{-1}$ (Hachiya et al., 2007), and that an amino acid contains one nitrogen element.

\subsection{Dry weight}

Yeast growth was followed by cell concentration (N) measurements using a flow cytometer. The corresponding dry weight (DW) was obtained by applying the correlation between N (cells. $\mathrm{l}^{-1}$ ) and DW (g. $\mathrm{l}^{-1}$ ) (1) previously established by La et al. (2019). 
$D W=3.25 \times 10^{-11} \times N$

1)

\subsection{Glucose, ethanol, and glycerol measurements}

Glucose, ethanol, and glycerol concentrations were measured by high-pressure liquid chromatography according to La et al. (2019).

\subsection{S. cerevisiae biomass composition}

According to Verduyn et al. (1990b), $100 \mathrm{~g}$ of $S$. cerevisiae is composed of $\mathrm{C}_{3.75} \mathrm{H}_{6.6} \mathrm{~N}_{0.63} \mathrm{O}_{2.10}$, which corresponds to $45 \%$ (w/w) carbon, $7 \%$ (w/w) hydrogen, $9 \%$ $(\mathrm{w} / \mathrm{w})$ nitrogen and 34\% (w/w) oxygen and 6\% (w/w) other elements. When the yeast chemical formula is fixed with a carbon content of 1 mole $\left(\mathrm{C}_{1} \mathrm{H}_{1.76} \mathrm{~N}_{0.17} \mathrm{O}_{0.56}\right)$, the yeast molar mass is $25 \mathrm{~g}$. mole ${ }^{-1}$ considering only the key elements ( $\mathrm{C}, \mathrm{H}, \mathrm{N}$ and $\mathrm{O}$ ) and $27 \mathrm{~g}$. mole ${ }^{-1}$ including other elements.

\section{The yeast model}

\subsection{Pathways}

The metabolic pathways considered in the model are depicted in Figure 2. Seven biological pathways emerge, and all ratios depicted in Figure 2 are expressed in moles and respect the carbon balance. The composition and molar mass of the main molecules are well-known from literature and the composition of yeast biomass is $\mathrm{CH}_{1.76} \mathrm{~N}_{0.17} \mathrm{O}_{0.56}+$ [other elements] with molar mass of $27 \mathrm{~g}$. mole ${ }^{-1}$. The glycerol and ethanol formation pathways are considered but pathways for the production of other by-products such as fusel alcohols are not within the scope of this study. A pathway is dedicated to biomass formation since glucose is the main carbon source for yeast biomass in the present study. The nitrogen supply for yeast biomass is ensured by peptone in the form of individual amino acids, small peptides (one to three units), and ammonium. The TCA cycle can also provide intermediate metabolites as precursors for the synthesis of amino acids, such as oxaloacetate for glutamate biosynthesis (Lee et al., 2011; Vemuri et al., 2007); however, we assume that this amino acid supply is negligible compared to that from peptone and intermediates from glycolysis. Therefore, the TCA cycle is implemented in this model for its main function, which is the production of energy precursors. According to Verduyn et al. (1990a), the yeast yield coefficient of ATP is approximately $28.3 g_{\text {yeast }}$. mole $e_{\text {ATP }}^{-1}$.

The kinetics of each pathway are expressed as a kinetics parameter multiplied by the yeast population, together with one or several factors accounting for possible limitations. The four compartments considered in our model were also outlined in Figure 2: the bioreactor liquid (substrate), the upper gaseous volume of the bioreactor (headspace), the inner cell (cytosol), and the mitochondrion. All concentrations in equations are expressed in SI units $\left(\right.$ mole $\mathrm{m}^{-3}$ ), even though, in order to ease the interpretation, the simulation and experimental values are plotted as mass or mole per liter, units commonly used in microbiological cultures. Besides, the limiting factors

This article is protected by copyright. All rights reserved. 
should be expressed in relevant quantities: mole. $\mathrm{m}^{-3}$ in the substrate, generic symbol $[C]$ and mole. mole ${ }_{\text {biomass }}^{-1}$ for quantities inside the cell or mitochondrion (quota), generic symbol $[C]^{*}$.

Regarding the ATP/ADP and NAD ${ }^{+} / \mathrm{NADH}$ balances, in addition to the source/sink terms tied to metabolic pathways, source terms must also be implemented to maintain a constant ratio per quantity of yeast. Indeed, the literature reports that $[\mathrm{NADH}]+\left[\mathrm{NAD}^{+}\right] \sim 6 \mu$ mole. $g_{\text {yeast }}^{-1}$ and $[\mathrm{ATP}]+[\mathrm{ADP}] \sim 5 \mu$ mole. $g_{\text {yeast }}^{-1}$ (Koç et al., 2004; Sakai et al., 1973; Sato et al., 2000; Suomalainen et al., 1965; Thomsson et al., 2005). Each constituent $C$ consumed by a biological reaction is likely to induce limitation when its relevant concentration $[C]$ (moles per volume for the external component) or $[C]^{*}$ (moles per mole of biomass, for the internal components) becomes too small. We also implemented the possibility to activate a reaction that is likely to produce a limiting resource, although this possibility was not applied in the present work. The classical Monod-like function is applied to all resources present in the substrate since its asymptotic behavior shape is indeed well adapted to resources that can be initially much higher than the limiting concentration (Figure 3). However, the case of $\mathrm{ATP} / \mathrm{ADP}$ and $\mathrm{NAD}^{+} / \mathrm{NADH}$ balances is quite different: as the accumulation of these quantities remains very low (some $\mu$ moles per gram of biomass), the limiting function should behave as a switch function represented by a smoothed stepwise function (Figure 3). The two functions used to express the limiting effects are as follows:

\section{A Monod-like function}

$\mathrm{M}(C)=\frac{C}{k_{C}+C}$

2)

Where $C$ is a generic concentration ([C] or $\left.[C]^{*}\right), k_{C}$ defines the steepness of the function near zero and the rate is divided by 2 when $C=k_{C}$.

A smooth stepwise function

$\mathrm{S}(C)=\frac{1+\tanh \left(\alpha\left(C / \Delta_{C}-1\right)\right)}{2}$

3)

The hyperbolic tangent function proposed here is a common function used in computational analysis to approach the Heaviside function as close as needed by a $C^{\infty}$ function. This function allows a shift effect over the narrow variation intervals experienced for ATP/ADP and NADH/NAD ${ }^{+}$. The Hill function, even with a large power, would have produced a similar effect, but on a logarithmic scale, not on a linear scale.

Each function is defined by two parameters. The shift value $\Delta_{C}$ defines the concentration value at which transition occurs as well as the steepness of this 
transition. Figure 3 depicts an example of function shapes with different parameter sets. The additional parameter of the function step allows the sharpness of the transition to be tuned.

Remark: The slope of the step function should be large enough for the value at origin to be close to zero. This is classical in computational analysis and ensures a penalty factor that is likely to freeze the reaction rate. For safety, we can also force the conditions $\mathrm{S}(0)=0$ and $\mathrm{S}\left(C_{\max }\right)=1$ :

$S(C)=\frac{\tanh \left(\alpha\left(C / \Delta_{C}-1\right)\right)-\tanh (-\alpha)}{\tanh \left(\alpha\left(C_{\max } / \Delta_{C}-1\right)\right)-\tanh (-\alpha)}$

4)

In the metabolic pathways described in Figure 2, the three compartments should be respected. Since ATP/ADP molecules are likely to pass through the mitochondrion wall, one unique stock of these constituents should be considered in the model. On the contrary, the $\mathrm{NAD}^{+}$to NADH transfer involved in the TCA cycle should be balanced inside the mitochondrion by respiration. Therefore, a specific stock of these molecules should be considered inside the mitochondrion (superscript ${ }^{\mathrm{M}}$ ). Finally, ten quantities are involved as inhibition effects. For each metabolic pathway, each constituent consumed by the reaction is systematically involved as a limiting factor (Table 2). With this rule, the set of kinetics takes the following form:

First step

$G \dot{3} P=\mu_{\text {yeast }} \times S\left([A T P]^{*}\right) \times M([G]) \times[$ yeast $]$

5)

Second step

$$
\begin{gathered}
\text { Gily }=\lambda_{G l y} \times S\left([N A D H]^{*}\right) \times M\left([G 3 P]^{*}\right) \times[\text { yeast }] \\
\text { Pyr }=\lambda_{\mathrm{Pyr}} \times \mathrm{S}\left(\left[\mathrm{NAD}^{+}\right]^{*}\right) \times S\left([A D P]^{*}\right) \times M\left([G 3 P]^{*}\right) \times[\text { yeast }]
\end{gathered}
$$

Third step

$$
\begin{gathered}
\dot{E}=\lambda_{E} \times S\left([N A D H]^{*}\right) \times M\left([\text { Pyr }]^{*}\right) \times[\text { yeast }] \\
\text { yeast }=\lambda_{\text {yeast }} \times S\left([\text { ATP }]^{*}\right) \times M\left([\text { Pyr }]^{*}\right) \times M([N]) \times[\text { yeast }] \\
T \dot{C} A=\lambda_{T C A} \times S\left([A D P]^{*}\right) \times S\left(\left[N A D^{+M}\right]^{*}\right) \times M\left([\text { Pyr }]^{*}\right) \times[\text { yeast }]
\end{gathered}
$$

This article is protected by copyright. All rights reserved. 
Mitochondrial respiration

$\operatorname{Resp}=\mu_{\text {Resp }} \times S\left([A D P]^{*}\right) \times S\left([N A D H]^{*}\right) \times M\left(\left[O_{2}\right]\right) \times[$ yeast $]$

8)

\subsection{Component balances}

As depicted in Figure 2, each biological pathway involves sink or source terms of components involved in the metabolic pathways. These terms are expressed in matrix forms. The first set of equations refers to the primary variables of the model, those who are directly produced or consumed by the successive transformations from glucose to the final products. The second set of equations (Equations 11 and 12) considers all other quantities considered in the present work.

This article is protected by copyright. All rights reserved. 


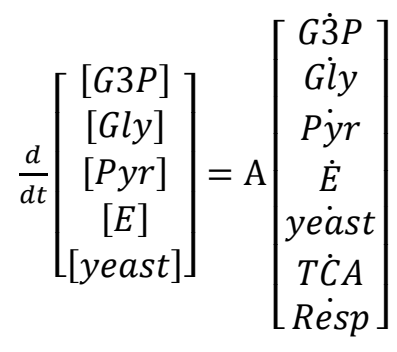

9)

$A=\left[\begin{array}{ccccccc}1 & -1 & -1 & 0 & 0 & 0 & 0 \\ 0 & 1 & 0 & 0 & 0 & 0 & 0 \\ 0 & 0 & 1 & -1 & -1 / 3 & -1 / 3 & 0 \\ 0 & 0 & 0 & 1 & 0 & 0 & 0 \\ 0 & 0 & 0 & 0 & 1 & 0 & 0\end{array}\right]$

10)

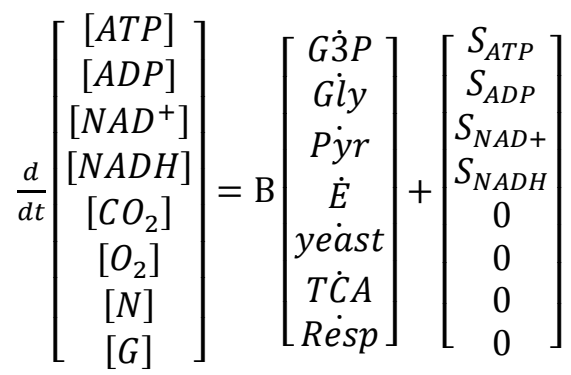

11)

$\mathrm{B}=\left[\begin{array}{ccccccc}-1 & 0 & 2 & 0 & -1 & 1 & 3 \\ 1 & 0 & -2 & 0 & 1 & -1 & -3 \\ 0 & 1 & -1 & 1 & 0 & -4 & 1 \\ 0 & -1 & 1 & -1 & 0 & 4 & -1 \\ 0 & 0 & 0 & 1 & 0 & 3 & 0 \\ 0 & 0 & 0 & 0 & 0 & 0 & -0.5 \\ 0 & 0 & 0 & 0 & -0.17 & 0 & 0 \\ -0.5 & 0 & 0 & 0 & 0 & 0 & 0\end{array}\right]$

12)

The final right-hand vector of Equation 11 represents the source terms required to ensure a constant concentration of $[A T P]^{*}+[A D P]^{*}$ and $\left[N A D^{+}\right]^{*}+[N A D H]^{*}$ per mole of yeast. For example, the source term of ATP reads as follows:

$S_{A T P}=[A T P]^{*} \times \frac{d[\text { yeast }]}{d t}$

13)

This article is protected by copyright. All rights reserved. 


\subsection{Inactivation of the TCA cycle in oxygen-limited conditions}

The NADH to $\mathrm{NAD}^{+}$transfer assured by respiration can be used either in the cytosol (for glycolysis) or in the mitochondrion (for the TCA cycle), and it is important to highlight the fact that the inner mitochondrial membrane is impermeable to NADH (von Jagow and Klingenberg, 1970). These facts raise an important question regarding the allocation of this transfer between these two compartments. However, this question has not yet been addressed to date. Instead, we simply assume that the TCA cycle is not active due to the Crabtree effect, so the NAD ${ }^{+} / \mathrm{NADH}$ balance inside the mitochondrion was discarded. Indeed, a high concentration of glucose seems to have an impact on the activities of some enzymes involved in the TCA cycle (Beck and Von Meyenburg, 1968; Fiechter et al., 1981). Moreover, de Alteriis et al. (2018) associated the Crabtree effect to the SICD (Sugar-Induced Cell Death) in order to highlight the link between high glucose uptake rate and ATP depletion. By integrating this novel interpretation of Crabtree effect into a dynamic study of the glycolytic flux, the authors explained that an enhanced glucose uptake leads to a down-regulation of respiration involving TCA cycle in order to refocus resources on fermentation pathway and maintain the ATP homeostasis.

Global mass balance calculations from our experimental study of the S. cerevisiae batch culture support the notion of TCA cycle inactivation. The main metabolism appeared to be fermentation since the maximal biomass formed was $3.25 g_{D W}$, resulting in a specific yield coefficient for glucose of $0.06 g_{\text {yeast }} . g_{\text {glucose }}^{-1}$ (Verduyn et al., 1990a). If one refines the analysis, the formation of $3.25 \mathrm{~g}$ of DW required the degradation of $3.7 g_{\text {glucose }}$ (carbon content of $46 \%$ according to elementary CHN/O analysis) using 0.042 mole of $\mathrm{NAD}^{+}$for biomass production (Equation 14). The maximal amount of glycerol produced at the end of fermentation (32 hours) was $1.5 \mathrm{~g}$ of glycerol (i.e. 0.016 mole), which implied the degradation of 0.008 mole of glucose and the generation of part of the required amount of $\mathrm{NAD}^{+}(0.016$ mole) (Equation 15), resulting in a 0.026 mole of $\mathrm{NAD}^{+}$shortfall that should have been supplied by respiration with external $\mathrm{NADH}$ dehydrogenase requesting $0.42 g_{\mathrm{O}_{2}}$ (Equation 16).

$0.021 C_{6} H_{12} O_{6}+0.084 A T P+0.042 N A D^{+} \rightarrow 0.126 C H_{1.76} N_{0.17} O_{0.56}+0.084 A D P+$ $0.042 \mathrm{NADH}$

$0.008 C_{6} H_{12} O_{6}+0.016 N A D H+0.016 H^{+} \rightarrow 0.016 C_{3} H_{8} O_{3}+0.016 N A D^{+}$

$0.026 \mathrm{NADH}+0.013 \mathrm{O}_{2}+0.026 \mathrm{H}^{+} \rightarrow 0.026 \mathrm{NAD}^{+}+0.026 \mathrm{H}_{2} \mathrm{O}$

Regarding the total amount of molecular oxygen available in the gaseous and liquid phases of the bioreactor ( $0.43 \mathrm{~g}$ ), a negligible amount of molecular oxygen was available to ensure NADH oxidation into $\mathrm{NAD}^{+}$in the TCA cycle (mitochondrial compartment). Therefore, we can assume that the TCA cycle was inactive in the present study.

\subsection{Oxygen balance}

This article is protected by copyright. All rights reserved. 
The total bioreactor volume is the sum of the liquid volume $V_{l i q}$ and the upper gaseous volume $\mathrm{V}_{\text {gas }}$, both of which contain an initial quantity of oxygen. Since the bioreactor is closed during the culture, an oxygen balance equation is required to know how the initial stock can be used by biological activity. The sink term $S_{\mathrm{O}_{2}}$ is solely due to mitochondrial respiration. According to the stoichiometric coefficients (see Equation 10 ), the oxygen consumption reads as:

$S_{O_{2}}=-0.5 \operatorname{Resp} \times V_{l i q} \quad\left(\right.$ mole. $\left.s^{-1}\right)$

\section{7)}

The time derivative of the oxygen contained in the liquid phase should account for this biological sink term, but also for the exchange between the liquid and gaseous phases. This mass flux $q_{O_{2}}$ is expressed using a mass transfer coefficient $\mathrm{h}_{\mathrm{m}}$ :

$q_{O_{2}}=h_{m} \frac{s}{R T}\left(P_{O_{2}}-h M_{O_{2}}\left[O_{2}\right]\right) \quad\left(\right.$ mole. $\left.s^{-1}\right)$

Where $S$ is the gas-liquid surface area in the bioreactor $\left(\mathrm{m}^{2}\right)$ and $h$ the Henry's constant $\left(\mathrm{Pa} . \mathrm{kg}^{-1} \cdot \mathrm{m}^{3}\right)$. Combining the two previous equations allows the time evolution of the oxygen in liquid to be obtained:

$\frac{d\left[O_{2}\right]}{d t}=\frac{q_{O_{2}}+S_{O_{2}}}{V_{l i q}} \quad\left(\right.$ mole. $\left.m^{-3} s^{-1}\right)$

Finally, one must account for the decreased partial pressure of oxygen in the gaseous phase induced by the flux $q_{O_{2}}$ :

$\frac{d P_{O_{2}}}{d t}=-q_{O_{2}} \frac{R T}{V_{g a s}} \quad\left(P a . s^{-1}\right)$

\subsection{Model parameters}

The model described in the previous section contains several parameters that must be supplied to the computational code. The parameters $h_{m}, S$, T, $V_{g a s}$, and $V_{\text {liq }}$ are specific to the bioreactor used for the experiment (Table 3). All stoichiometric coefficients, as reported in Figure 2, are supplied to the code as matrix A of Equation 10. Finally, two sets of parameters remain to be defined: the kinetics parameters and the threshold values of the limiting factors. The kinetics parameters were defined as follows: assuming that the collection of sugar from the substrate is the most difficult task for yeast, the observed maximum growth rate $\mu_{\text {max }}$, defined during exponential growth, was allocated to the first step of glycolysis. This assumption is consistent with the concept of harvesting volume proposed by Quéméner and Bouchez (2014). All other kinetics parameters involving pathways inside the cell are assumed to be rapid (20 times $\mu_{\max }$ ). The kinetics of respiration was adjusted from the measured variation 
of $\mathrm{O}_{2}$ in the substrate. The fitted value is in good agreement with literature data (Hagman and Piškur, 2015).

Regarding the threshold values of the Monod-like functions, the classical value $(0.1 \mathrm{~g}$ per liter) was again adopted for the first step of glycolysis. The Monod constants $K_{C}$ for other components are very small (namely for the intermediate components ATP, G3P, NAD ${ }^{+}$, and Pyr), meaning that these components are rapidly consumed after being produced, knowing that these values have very little effect on the kinetics. The parameter values of the stepwise functions were determined to obtain a rapid switch when the concentration becomes low in terms of the sum per gram of cells $\left(\right.$ tot $_{N A D^{+}}=[N A D H]+\left[N A D^{+}\right]=6 \mu$ mole. $\left.g_{\text {yeast }}^{-1}\right)$ and tot $t_{A T P}=[A T P]+[A D P]=$ $\left.5 \mu \mathrm{mole} . g_{\text {yeast }}^{-1}\right) . \Delta_{\mathrm{C}}$ was taken as $5 \%$ of this total content. $\alpha$ was set to 5 to ensure that the function equals zero at zero concentration. For these balances, the total content per cell is so small that the value of $\Delta_{C}$ has absolutely no effect on the model results: the time evolution equation is indeed forced to balance the source and sink terms at any time. The full set of parameters are reported in Table 3.

Despite these restrictive parameters, the partition of each concurrent pathway can be predicted due to the limitation factors and stoichiometric coefficients, which are wellknown from literature. Among the entire set of model parameters, only four parameters were unknown and had a significant effect on the modeling results. These parameters were highlighted in bold in Table 3:

- $\lambda_{\text {Gly }}$ was adjusted to determine the measured concentration of glycerol at the end of the experiment. However, this parameter has quite a moderate effect since this pathway is activated only at the end of yeast growth when the G3P content becomes significant due to the limitation of the pyruvate pathway. The adjusted value is consistent with data from the literature.

- $\lambda_{E}$ needed to be different from the biomass pathway to give a certain priority to biomass production in the use of pyruvate. The obtained value cannot be directly compared to literature data since our model accounts for sequential pathways.

- $\quad \mu_{\text {Resp }}$ was fitted to determine the experimental decrease of dissolved oxygen. The kinetics of this process is very important at the beginning of growth since it provides the cell with ATP and NAD ${ }^{+}$and facilitates a rapid increase in biomass.

- The initial value of $K_{N}$, based on literature data, gave an insufficient reduction in growth when nitrogen is depleted. We increased this parameter up to $4 \times 10^{-3}$ mole. $\mathrm{l}^{-1}$.

We had also to increase $\mu_{\text {yeast }}$ by $10 \%$ (0.30 instead of 0.27$)$ for the modelled growth curve to lie exactly on the experimental curve. However, this is not necessary to claim that the model is predictive. This was performed for readers to more easily compare the kinetics of yeast population and the kinetics of ethanol production. In addition, since $\mu_{\text {yeast }}$ is applied to the first step of glycolysis, the successive pathways in series are likely to slightly affect the global dynamics of yeast populations.

\section{Results and discussion}

This article is protected by copyright. All rights reserved. 


\subsection{Comparison with experimental data}

The first simulation accounts for the formulation with the full set of limiting factors (Figure 4). At the beginning of the culture, the available oxygen is used for respiration, which produces $\mathrm{ATP}$ and $\mathrm{NAD}^{+}$. $\mathrm{NAD}^{+}$is needed to activate the pyruvate pathway. However, this pathway also produces ATP very efficiently. As a result, the level of ADP decreases and eventually limits the pyruvate pathway. The depletion of ADP limits also respiration, which is not able to consume the stock of oxygen present at the beginning of the culture. Throughout the culture, the low pyruvate kinetics is unable to balance G3P production. The high and unrealistic level of G3P activates the glycerol pathway, which is required to produce $\mathrm{NAD}^{+}$as the ethanol pathway is not very active due to a limited concentration of pyruvate.

It seems unrealistic that excess of energy blocks the main path toward biomass production. Assuming that the excess ATP could be used to produce internal reserves, we add a sink term of ATP to mimic this possibility, which is activated when the level of ADP is too low. The yeast model now accurately predicts the experiment regarding the comprehensive set of experimental data (Figure 5). This indicates that the limitation factors (except ADP) and stoichiometric coefficients could be used with the current experimental results to predict glucose, biomass, ethanol, glycerol, and oxygen profiles. The prediction of components that were not measured experimentally (ATP, $\mathrm{NAD}^{+}$, G3P, Pyruvate, and nitrogen) helped in interpreting and understanding the biological activity. $S$. cerevisiae growth can be divided into three distinct stages, while the transition from one phase to the next is explained by changes in the limiting components.

The first stage occurred during the first 20 hours when oxygen content is sufficient to keep the mitochondrial respiration pathway active while producing enough ATP and $\mathrm{NAD}^{+}$to activate the biomass pathways (Glucose $\rightarrow$ G3P $\rightarrow$ Pyruvate $\rightarrow$ Biomass). Respiration allows the yeast population to increase exponentially at a rate similar to the experimental results. Notably, such correct kinetics are obtained solely by supplying the experimental value of $\mu_{\max }$ to the first step of glycolysis. Although the respiration pathway is the main booster of biomass pathways during this initial stage, the ethanol pathway is also active and produces the additional $\mathrm{NAD}^{+}$needed for the pyruvate pathway. As previously mentioned, we had to limit the kinetics of fermentation (2 times slower than the biomass pathway) to obtain the experimental delay between yeast and ethanol: the yeast population clearly increases before ethanol. During this phase, the glycerol pathway remains slow due to the low level of G3P.

Once oxygen depletion occurs, the lack of ATP and $\mathrm{NAD}^{+}$produced by mitochondrial respiration activity reduces biomass production. During the second stage (20-30 hours), oxygen was completely depleted and the production of $\mathrm{NAD}^{+}$is only ensured by the ethanol and glycerol pathways with a smaller production rate, resulting in reduced yeast population growth. The slight decrease in $\mathrm{NAD}^{+}$visible after 20 hours has a great effect on the step function and reduces the pyruvate pathway. This is confirmed by the accumulation of G3P during this period. The higher level of G3P triggers the glycerol pathway, as proven by a rapid increase in the glycerol 
concentration. This trend is in agreement with the glycerol concentration found at the end of the experiment. The experimental data lack of intermediate points as the glycerol level was too low for detection in the samples collected before 30 hours of culture. Moreover, the production of ATP is now solely ensured by the pyruvate pathway, which is slow. The ATP graph depicts an ATP depletion just after 20 hours and for a short time interval.

After 30 hours (third stage), yeast growth stopped despite ATP and NAD ${ }^{+}$still being available to $S$. cerevisiae. The nitrogen plot from simulation results suggests that nitrogen depletion is responsible for the inhibition of the biomass pathway. Therefore, nitrogen is the second and ultimate limiting yeast growth factor. The short period of ATP depletion ends because the biomass pathway is the most demanding in ATP. The final yeast population was consistent with the experiment, which is consistent since we entered the same initial value of nitrogen in the model as in the experiment. In response to nutrient limitation, yeast generally accumulates glycogen and trehalose during fermentation. Then, at the end of yeast growth, the excess of ATP and NAD ${ }^{+}$ could subsequently be involved in the degradation of these internal reserves for cell maintenance (François and Parrou, 2001; Lillie and Pringle, 1980). This process was not integrated into our model.

In order to further analyze the intricate coupling formulated in our model, two additional simulations were performed: one simulation without mitochondrial respiration and one simulation without the $\mathrm{NAD}^{+} / \mathrm{NADH}$ balance.

\subsection{Simulation without mitochondrial respiration}

The same test was then run without the mitochondrial respiration pathway (Figure 6). This pathway was simply blocked in the model. Consequently, oxygen was not used and $\mathrm{NAD}^{+}$production through the respiration pathway could not occur. This lack of electron carriers results in the pyruvate pathway being blocked, thus almost completely limiting yeast growth. This result tells us that mitochondrial respiration is mandatory to ensure yeast growth by the production of electron carriers. Yeast growth limitation results also in a cessation of fermentation activity, which results in excess glucose remaining in the medium. This is a common phenomenon in winemaking known as stuck fermentation. Oxygen limitation is generally described as the cause of a deficiency in cell membrane synthesis and, consequently, the yeast growth (Bisson, 1999; Blateyron and Sablayrolles, 2001; Julien et al., 2000; Sablayrolles et al., 1996). However, by removing the respiration pathway in our simulation, the blockage of biomass production is explained by the lack of electron carrier. This should therefore be also considered as the limiting factor for yeast growth in stuck fermentation, probably before the oxygen depletion is severe enough to block membrane synthesis.

In order to obtain realistic kinetics in the simulation, we would have to boost all kinetics by a factor 1.3 and the glycerol pathway by a factor 10 . In doing so, the glycerol pathway would be used instead of respiration to produce enough $\mathrm{NAD}^{+}$to activate the pyruvate pathway and, subsequently, the biomass pathway. As a

This article is protected by copyright. All rights reserved. 
consequence of these factor changes, the glycerol content at the end of the simulation would be much higher than in the experimental measurement $\left(0.7 \mathrm{~g} . ~^{-1}\right.$ instead of 0.3$)$.

\subsection{Simulation without limiting effects of $N A D^{+}$}

Finally, we performed a test in which we cancelled any effect of NAD ${ }^{+}$. This configuration was implemented in the simulation code by modifying the $\mathrm{NAD}^{+} / \mathrm{NADH}$ balance in such a way to keep both concentrations equal to $0.5 *$ tot $_{N_{A D^{+}}} \times[$yeast $]$. In addition to the availability of reactants, the kinetics were controlled only by the ATP content. In this case, most of the kinetics remain in good agreement with the experimental data. As evident in Figure 7, the main trends remain quite good, except for the glycerol pathway, which is much smaller in this case (10 times smaller than in the experiment). Since the G3P $\rightarrow$ pyruvate pathway is no longer limited by the availability of $\mathrm{NAD}^{+}$, G3P is more devoted to the pyruvate pathway than toward glycerol. The glycerol pathway does not need to be promoted any further to produce $\mathrm{NAD}^{+}$. This is one additional prove to the benefit of the electron carrier balance to correctly trigger the different metabolic pathways. The respiration and the ethanol pathways supplied sufficient ATP, while NAD ${ }^{+}$had no more limiting effect on biomass pathways; therefore, nitrogen is now the sole limiting growth factor. By reducing the number of yeast-limiting growth factors to one, the specific growth rate is slightly higher than the experimental results. One can also remark that ethanol production appears sooner, with a reduced delay between yeast growth and ethanol production.

\section{Conclusion}

The model developed in the present work has successfully proven its prediction potential for yeast fermentation. Resource allocation was consistent with experimental results simply due to the limiting factors of the seven metabolic pathways. The model was built in such a way to be able to save and plot the intensity of each component and the rates of reaction over time, making this model an essential tool to understand the interactions between the different metabolic pathways. This model pinpoints the key role of ATP and the electron carrier $\mathrm{NAD}^{+}$to trigger the different metabolic pathways in yeast culture. The crucial role of oxygen and mitochondrial respiration (without the TCA cycle) on the dynamics of yeast populations was also highlighted. Further developments to this model are currently in progress by our team, including the implementation of the TCA cycle, which will require a new $\mathrm{NAD}^{+} / \mathrm{NADH}$ balance to be added in the mitochondrion compartment. The present version is solely driven by limiting factors. The question of possible promoting effects, which could be tuned based on the global optimization of resources, is also part of our ongoing work.

\section{Acknowledgements}

The authors would like to thank Département de la Marne, Région Grand Est, and Grand Reims for their financial support.

\section{References}

This article is protected by copyright. All rights reserved. 
Aiba S, Shoda M, Nagatani M. 1968. Kinetics of product inhibition in alcohol fermentation. Biotechnol. Bioeng. 10:845-864.

http://doi.wiley.com/10.1002/bit.260100610.

de Alteriis E, Cartenì F, Parascandola P, Serpa J, Mazzoleni S. 2018. Revisiting the Crabtree/Warburg effect in a dynamic perspective: a fitness advantage against sugar-induced cell death. Cell Cycle 17:688-701. https://doi.org/10.1080/15384101.2018.1442622.

Bakker BM, Overkamp KM, van Maris AJA, Kötter P, Luttik MAH, van Dijken JP, Pronk JT. 2001. Stoichiometry and compartmentation of NADH metabolism in Saccharomyces cerevisiae. FEMS Microbiol. Rev. 25:15-37.

Beck C, Von Meyenburg HK. 1968. Enzyme pattern and aerobic growth of Saccharomyces cerevisiae under various degrees of glucose limitation. $J$. Bacteriol. 96:479-486.

Bisson LF. 1999. Stuck and sluggish fermentations. Am. J. Enol. Vitic. 50:107-119.

Blateyron L, Sablayrolles JM. 2001. Stuck and slow fermentations in enology: statistical study of causes and effectiveness of combined additions of oxygen and diammonium phosphate. J. Biosci. Bioeng. 91:184-189. https://linkinghub.elsevier.com/retrieve/pii/S1389172301800633.

Bovee JP, Strehaiano P, Goma G, Sevely Y. 1984. Alcoholic fermentation: Modelling based on sole substrate and product measurement. Biotechnol. Bioeng. 26:328334. http://doi.wiley.com/10.1002/bit.260260406.

Chaney D, Rodriguez S, Fugelsang K, Thornton R. 2006. Managing high-density commercial scale wine fermentations. J. Appl. Microbiol. 100:689-698. http://doi.wiley.com/10.1111/j.1365-2672.2006.02839.x.

Coleman MC, Fish R, Block DE. 2007. Temperature-Dependent Kinetic Model for Nitrogen-Limited Wine Fermentations. Appl. Environ. Microbiol. 73:5875-5884. http://aem.asm.org/cgi/doi/10.1128/AEM.00670-07.

Cramer AC, Vlassides S, Block DE. 2002. Kinetic model for nitrogen-limited wine fermentations. Biotechnol. Bioeng. 77:49-60.

http://doi.wiley.com/10.1002/bit.10133.

Dashko S, Zhou N, Compagno C, Piškur J. 2014. Why, when, and how did yeast evolve alcoholic fermentation? FEMS Yeast Res. 14:826-832. https://academic.oup.com/femsyr/article-lookup/doi/10.1111/1567-1364.12161.

De Deken RH. 1966. The Crabtree Effect: A Regulatory System in Yeast. J. Gen. Microbiol. 44:149-156. http://mic.microbiologyresearch.org/content/journal/micro/10.1099/0022128744-2-149.

This article is protected by copyright. All rights reserved. 
van Dijken JP, Weusthuis RA, Pronk JT. 1993. Kinetics of growth and sugar consumption in yeasts. Antonie Van Leeuwenhoek 63:343-352.

Fiechter A, Fuhrmann GF, Käppeli O. 1981. Regulation of Glucose Metabolism in Growing Yeast Cells. In:. Adv. Microb. Physiol. Elsevier, Vol. 22, pp. 123-183. https://linkinghub.elsevier.com/retrieve/pii/S0065291108603276.

François J, Parrou JL. 2001. Reserve carbohydrates metabolism in the yeast Saccharomyces cerevisiae. FEMS Microbiol. Rev. 25:125-145. https://academic.oup.com/femsre/article-lookup/doi/10.1111/j.15746976.2001.tb00574.x.

Giovanelli G, Peri C, Parravicini E. 1996. Kinetics of grape juice fermentation under aerobic and anaerobic conditions. Am. J. Enol. Vitic. 47:429-434.

Hachiya T, Terashima I, Noguchi KO. 2007. Increase in respiratory cost at high growth temperature is attributed to high protein turnover cost in Petunia $\mathrm{x}$ hybrida petals. Plant. Cell Environ. 30:1269-1283.

Hagman A, Piškur J. 2015. A study on the fundamental mechanism and the evolutionary driving forces behind aerobic fermentation in yeast. PLoS One 10:1-24.

Hagman A, Säll T, Piškur J. 2014. Analysis of the yeast short-term Crabtree effect and its origin. FEBS J. 281:4805-4814.

Holzberg I, Finn RK, Steinkraus KH. 1967. A kinetic study of the alcoholic fermentation of grape juice. Biotechnol. Bioeng. 9:413-427.

Hynne F, Danø S, Sørensen PG. 2001. Full-scale model of glycolysis in Saccharomyces cerevisiae. Biophys. Chem. 94:121-163.

von Jagow G, Klingenberg M. 1970. Pathways of hydrogen in mitochondria of Saccharomyces carlsbergensis. Eur. J. Biochem. 12:583-592.

Julien A, Roustan J-L, Dulau L, Sablayrolles J-M. 2000. Comparison of Nitrogen and Oxygen Demands of Enological Yeasts: Technological Consequences. Am. J. Enol. Vitic. 51:215-222. http://www.ajevonline.org/content/51/3/215.

Koç A, Wheeler LJ, Mathews CK, Merrill GF. 2004. Hydroxyurea arrests DNA replication by a mechanism that preserves basal dNTP pools. J. Biol. Chem. 279:223-230.

La A, Perré P, Taidi B. 2019. Process for symbiotic culture of Saccharomyces cerevisiae and Chlorella vulgaris for in situ CO2 mitigation. Appl. Microbiol. Biotechnol. 103:731-745.

Lee YJ, Jang JW, Kim KJ, Maeng PJ. 2011. TCA cycle-independent acetate metabolism via the glyoxylate cycle in Saccharomyces cerevisiae. Yeast 28:153-

This article is protected by copyright. All rights reserved. 
166.

Lillie SH, Pringle JR. 1980. Reserve carbohydrate metabolism in Saccharomyces cerevisiae: responses to nutrient limitation. J. Bacteriol. 143:1384-1394.

Liu C-G, Lin Y-H, Bai F-W. 2011. A kinetic growth model for Saccharomyces cerevisiae grown under redox potential-controlled very-high-gravity environment. Biochem. Eng. J. 56:63-68.

López A, Secanell P. 1992. A simple mathematical empirical model for estimating the rate of heat generation during fermentation in white-wine making. Int. J. Refrig. 15:276-280.

Nielsen K, Sørensen PG, Hynne F, Busse H-G. 1998. Sustained oscillations in glycolysis: an experimental and theoretical study of chaotic and complex periodic behavior and of quenching of simple oscillations. Biophys. Chem. 72:49-62.

Overkamp KM, Bakker BM, Kötter P, van Tuijl A, de Vries S, van Dijken JP, Pronk JT. 2000. In Vivo Analysis of the Mechanisms for Oxidation of Cytosolic NADH by Saccharomyces cerevisiae Mitochondria. J. Bacteriol. 182:2823-2830.

Pfeiffer T, Morley A. 2014. An evolutionary perspective on the Crabtree effect. Front. Mol. Biosci. 1:1-6.

Quéméner ED Le, Bouchez T. 2014. A thermodynamic theory of microbial growth. ISME J. 8:1747-1751.

Richter O, Betz A, Giersch C. 1975. The response of oscillating glycolysis to perturbations in the NADH/NAD system: a comparison between experiments and a computer model. Biosystems 7:137-146.

Rizzi M, Baltes M, Theobald U, Reuss M. 1997. In vivo analysis of metabolic dynamics in Saccharomyces cerevisiae: II. Mathematical model. Biotechnol. Bioeng. 55:592-608.

Rosenfeld E, Beauvoit B, Blondin B, Salmon J. 2003. Oxygen Consumption by Anaerobic Saccharomyces cerevisiae under Enological Conditions: Effect on Fermentation Kinetics. Appl. Environ. Microbiol. 69:113-121.

Sablayrolles JM. 1986. Evaluation des besoins en oxygene de fermentations alcooliques en conditions oenologiques simulees. Sci. Alim. 6:373-383.

Sablayrolles J-M, Dubois C, Manginot C, Roustan J-L, Barre P. 1996. Effectiveness of combined ammoniacal nitrogen and oxygen additions for completion of sluggish and stuck wine fermentations. J. Ferment. Bioeng. 82:377-381.

Sakai T, Uchida T, Chibata I. 1973. Accumulation of nicotinamide adenine dinucleotide in baker's yeast by secondary culture. Agric. Biol. Chem. 37:1049-

This article is protected by copyright. All rights reserved. 
1056.

Sato K, Yoshida Y, Hirahara T, Ohba T. 2000. On-line measurement of intracellular ATP of Saccharomyces cerevisiae and pyruvate during sake mashing. J. Biosci. Bioeng. 90:294-301.

Suomalainen H, Bjorklund A, Vihervaara K, Oura E. 1965. Nicotinic acid and nicotinamide adenine dinucleotide contents of baker's yeast in changing culture conditions. J. Inst. Brew. 71:221-226.

Thomsson E, Gustafsson L, Larsson C. 2005. Starvation response of Saccharomyces cerevisiae grown in anaerobic nitrogen-or carbon-limited chemostat cultures. Appl. Environ. Microbiol. 71:3007-3013.

Vemuri GN, Eiteman MA, McEwen JE, Olsson L, Nielsen J. 2007. Increasing NADH oxidation reduces overflow metabolism in Saccharomyces cerevisiae. Proc. Natl. Acad. Sci. 104:2402-2407.

Verduyn C, Postma E, Scheffers A, Dijken J. 1990a. Energetics of Saccharomyces cerevisiae in anaerobic glucose-limited chemostat cultures. J. Gen. Microbiol. 136:405-412.

Verduyn C, Postma E, Scheffers A, Dijken J. 1990b. Physiology of Saccharomyces cerevisiae in Anaerobic Glucose-Limited Chemostat Cultures. J. Gen. Microbiol. 136:395-403.

http://mic.microbiologyresearch.org/content/journal/micro/10.1099/00221287136-3-395.

Verduyn C, Zomerdijk TPL, Dijken JP, Scheffers WA. 1984. Continuous measurement of ethanol production by aerobic yeast suspensions with an enzyme electrode. Appl. Microbiol. Biotechnol. 19:181-185.

Yalçin SK, Özbas ZY. 2004. Effects of different substrates on growth and glycerol production kinetics of a wine yeast strain Saccharomyces cerevisiae Narince 3. Process Biochem. 39:1285-1291.

This article is protected by copyright. All rights reserved. 


\section{Tables}

Table 1. Nomenclature and initial conditions of quantities

\section{Symbol Quantity}

ATP

Adenosine triphosphate

ADP

Adenosine diphosphate

$\mathrm{NAD}^{+} \quad$ Oxidized form of nicotinamide adenine dinucleotide

NADH Reduced form of nicotinamide adenine dinucleotide

G

G3P

Pyr

Pyruvate

$\mathrm{N} \quad$ Nitrogen assimilable from peptone

$\mathrm{O}_{2} \quad$ Molecular oxygen

yeast

E

Ethanol

Gly

Glycerol
67.5

$\mu$ mole. mole yeast

$81 \mu$ mole. mole ${ }_{\text {yeast }}^{-1}$

$81 \mu$ mole. mole yeast

$5.6 \times 10^{-2}$ mole. $\mathrm{m}^{-3}$

0 mole. $\mathrm{m}^{-3}$

0 mole. $\mathrm{m}^{-3}$

$4.6 \times 10^{-3}$ mole. $\mathrm{m}^{-3}$

$2.5 \times 10^{-4}$ mole. $\mathrm{m}^{-3}$

$3.7 \times 10^{-4}$ mole. $\mathrm{m}^{-3}$

0 mole. $\mathrm{m}^{-3}$

\section{Symbol Variables}

SI units

$h$

Henry's constant

Pa. $\mathrm{kg}^{-1} \cdot \mathrm{m}^{3}$ 


$\begin{array}{lll}h_{m} & \text { Mass transfer coefficient } & - \\ M & \text { Molar mass } & \text { kg.mole }^{-1} \\ P & \text { Pressure } & \mathrm{Pa} \\ S & \text { Gas-liquid surface area } & \mathrm{m}^{2} \\ V & \text { Volume } & \mathrm{m}^{3} \\ {[C]} & \text { Concentration of C in liquid } & {\text { mole. } \mathrm{m}^{-3}}^{3} \\ {[C]^{*}} & \text { Concentration of C in yeast } & \text { mole. mole }_{\text {biomass }} \\ \dot{P} & & \text { Rate of pathway P }\end{array}$

\section{Subscripts}

liq $\quad$ liquid

gas

gas

Table 2. The expression of limiting factors involved in the seven metabolic pathways ( $\mathrm{M}$ for Monod-like function and $\mathrm{S}$ is for stepwise function).

\begin{tabular}{|l|c|c|c|c|c|c|c|c|c|c|}
\hline Pathway & ATP & ADP & NAD $^{+}$ & NADH & $\begin{array}{c}\mathrm{NAD}^{+} \\
\text {M }\end{array}$ & Glu & G3P & Pyr & N & $\mathrm{O}_{2}$ \\
\hline G3P & $\mathrm{S}$ & & & & & $\mathrm{M}$ & & & & \\
\hline Glycerol & & & & $\mathrm{S}$ & & & $\mathrm{M}$ & & & \\
\hline Pyruvate & & $\mathrm{S}$ & $\mathrm{S}$ & & & & $\mathrm{M}$ & & & \\
\hline
\end{tabular}

This article is protected by copyright. All rights reserved. 


\begin{tabular}{|l|c|c|c|c|c|c|c|c|c|c|}
\hline Ethanol & & & & S & & & & M & & \\
\hline Biomass & $\mathrm{S}$ & & & & & & & $\mathrm{M}$ & $\mathrm{M}$ & \\
\hline TCA cycle & & $\mathrm{S}$ & & & $\mathrm{S}$ & & & $\mathrm{M}$ & & \\
\hline Respiration & & $\mathrm{S}$ & & $\mathrm{S}$ & & & & & & $\mathrm{M}$ \\
\hline
\end{tabular}

Table 3. Kinetics parameters associated with metabolic pathways, threshold constants of the limiting functions $\left(\mathrm{k}_{\mathrm{C}}\right.$ or $\left.\Delta_{\mathrm{C}}\right)$ and bioreactor configuration. Values in bold are adjusted parameters.

\begin{tabular}{ll} 
Parameters $\quad$ Value $\quad$ Literature value \\
\hline
\end{tabular}

Kinetics parameters associated with metabolic pathways

\begin{tabular}{|c|c|c|}
\hline$\mu_{\text {yeast }}$ & $0.30\left(\mathrm{~h}^{-1}\right)$ & 0.27 (our experimental data) \\
\hline$\lambda_{G l y}$ & $0.012\left(h^{-1}\right)$ & 0.01 - 0.03 (Yalçin and Özbas, 2004) \\
\hline$\lambda_{\text {Pyr }}$ & $20 \times \mu_{\text {yeast }}\left(h^{-1}\right)$ & - \\
\hline$\lambda_{E}$ & $\mathbf{1 0} \times \mu_{\text {yeast }}\left(\mathrm{h}^{-1}\right)$ & 0.3 (Cramer et al., 2002) \\
\hline$\lambda_{\text {yeast }}$ & $20 \times \mu_{\text {yeast }}\left(\mathrm{h}^{-1}\right)$ & - \\
\hline$\lambda_{T C A}$ & $20 \times \mu_{\text {yeast }}\left(h^{-1}\right)$ & - \\
\hline$\mu_{\text {Resp }}$ & $7.7 \times 10^{-2}\left(h^{-1}\right)$ & $9.6 \times 10^{-2}$ (Hagman and Piškur, 2015) \\
\hline
\end{tabular}

Threshold constants of the limiting functions $\left(k_{C}\right.$ or $\left.\Delta_{C}\right)$

This article is protected by copyright. All rights reserved. 


\begin{tabular}{|c|c|c|}
\hline$\Delta_{\mathrm{ATP}}$ & $0.05 \times \operatorname{tot}_{\mathrm{ATP}}$ & - \\
\hline$\Delta_{\mathrm{ADP}}$ & $0.05 \times \operatorname{tot}_{\mathrm{ATP}}$ & - \\
\hline$\Delta_{\mathrm{NAD+}}$ & $0.05 \times \operatorname{tot}_{\mathrm{NAD}}$ & - \\
\hline$\Delta_{\mathrm{NADH}}$ & $0.05 \times \operatorname{tot}_{\mathrm{NAD}}$ & - \\
\hline $\mathrm{k}_{\mathrm{G}}$ & $1.8 \times 10^{-1} \mathrm{~g} . \mathrm{l}^{-1}$ & $\begin{array}{l}1.8 \times 10^{-1} \mathrm{~g}^{-1} \mathrm{l}^{-1} \text { (van Dijken et al., } \\
1993 \text { ) }\end{array}$ \\
\hline $\mathrm{k}_{\mathrm{G} 3 \mathrm{P}}$ & $\begin{array}{l}2 \times 10^{-5} \text { mole. } \\
\text { mole }^{-1}\end{array}$ & - \\
\hline $\mathrm{k}_{\text {Pyr }}$ & $\begin{array}{l}2 \times 10^{-5} \text { mole. } \\
\text { mole }^{-1}\end{array}$ & - \\
\hline $\mathrm{k}_{\mathrm{N}}$ & $4 \times 10^{-3}$ mole. $~^{-1}$ & $7 \times 10^{-4}$ mole. $\mathrm{l}^{-1}$ (Cramer et al., 2002) \\
\hline $\mathrm{k}_{\mathrm{O}_{2}}$ & $3 \times 10^{-3}$ mole. $~^{-1}$ & - \\
\hline \multicolumn{3}{|c|}{ Bioreactor configuration } \\
\hline$h_{m}$ & $1 \times 10^{-2}$ & \\
\hline$S$ & $2 \times 10^{-2}\left(\mathrm{~m}^{2}\right)$ & \\
\hline$T$ & $293(\mathrm{~K})$ & \\
\hline$V_{\text {gas }}$ & $1.3(\mathrm{l})$ & \\
\hline$V_{\text {liq }}$ & $5(\mathrm{l})$ & \\
\hline
\end{tabular}

This article is protected by copyright. All rights reserved. 


\section{Figures}

Figure 1. A schematic diagram of the yeast cell and its growth limitations.

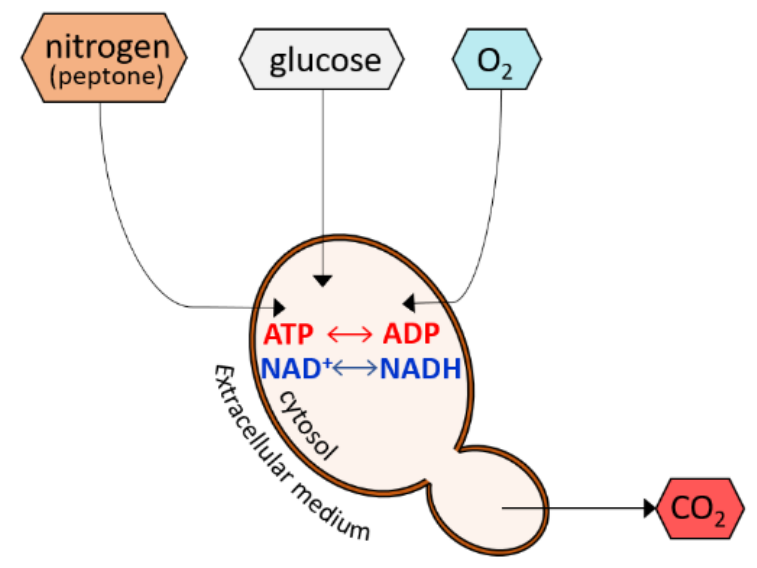

Figure 2. A schematic diagram of the metabolic pathways and the 4 compartments (gas, liquid, yeast and mitochondrion) implemented in the present modeling strategy. All numeric ratios are in moles.

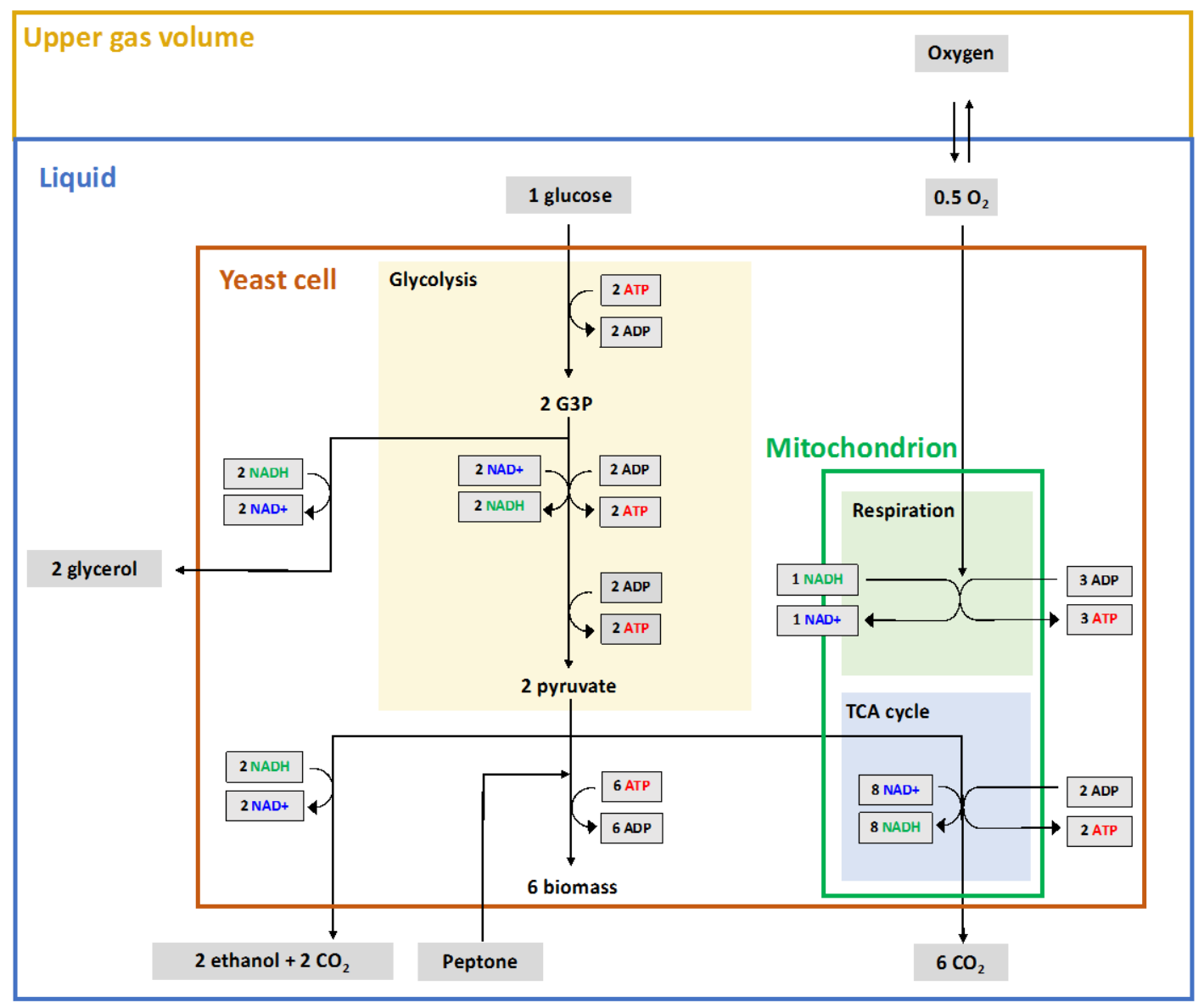

This article is protected by copyright. All rights reserved. 
Figure 3. The shape of functions used to affect reaction rates.

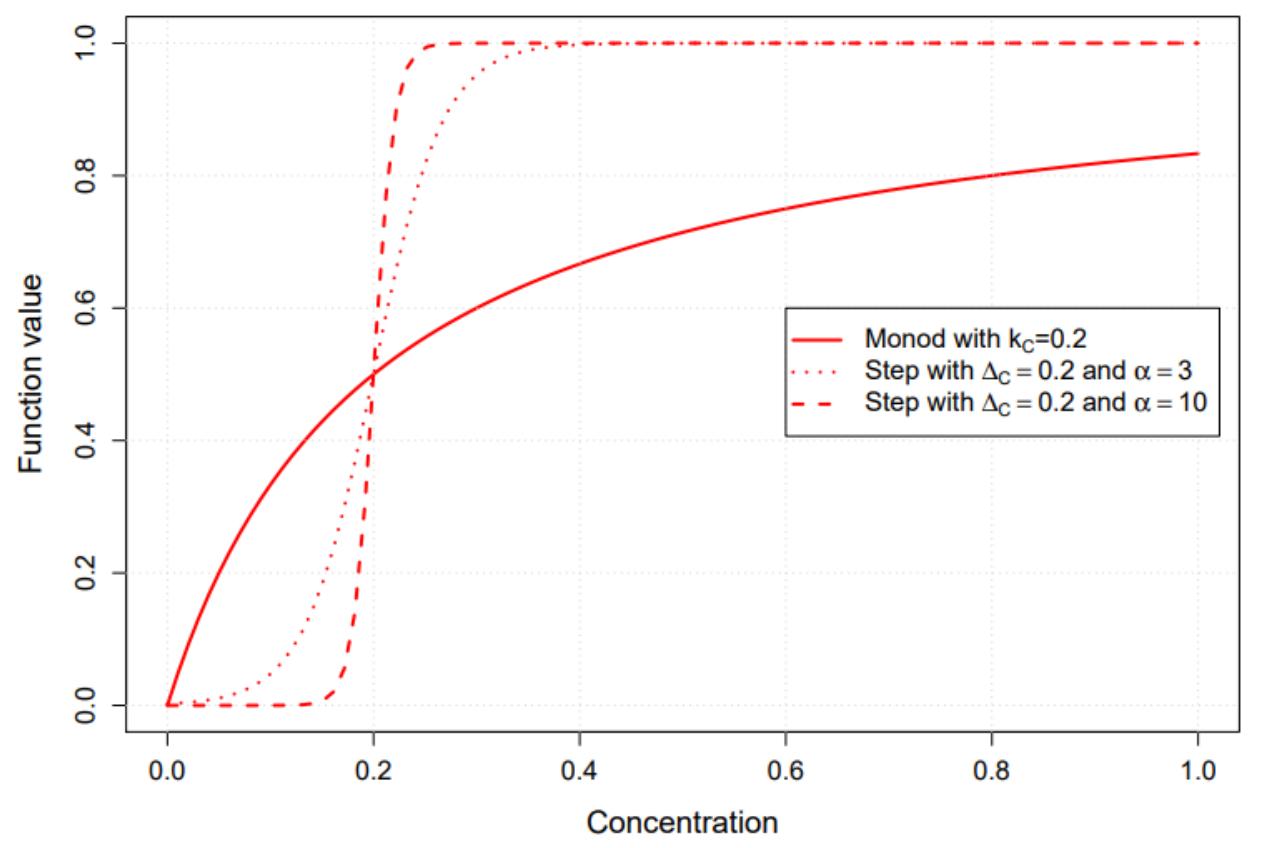

This article is protected by copyright. All rights reserved. 
Figure 4. Simulation results with the modeling strategy described in the previous section. The yeast growth is lowered by the depletion of ADP. This is due to an excess of energy (ATP) because the total amount of ATP plus ADP per cell is constant. This needed to be corrected because it is not consistent to block the pathways with an excess of energy.
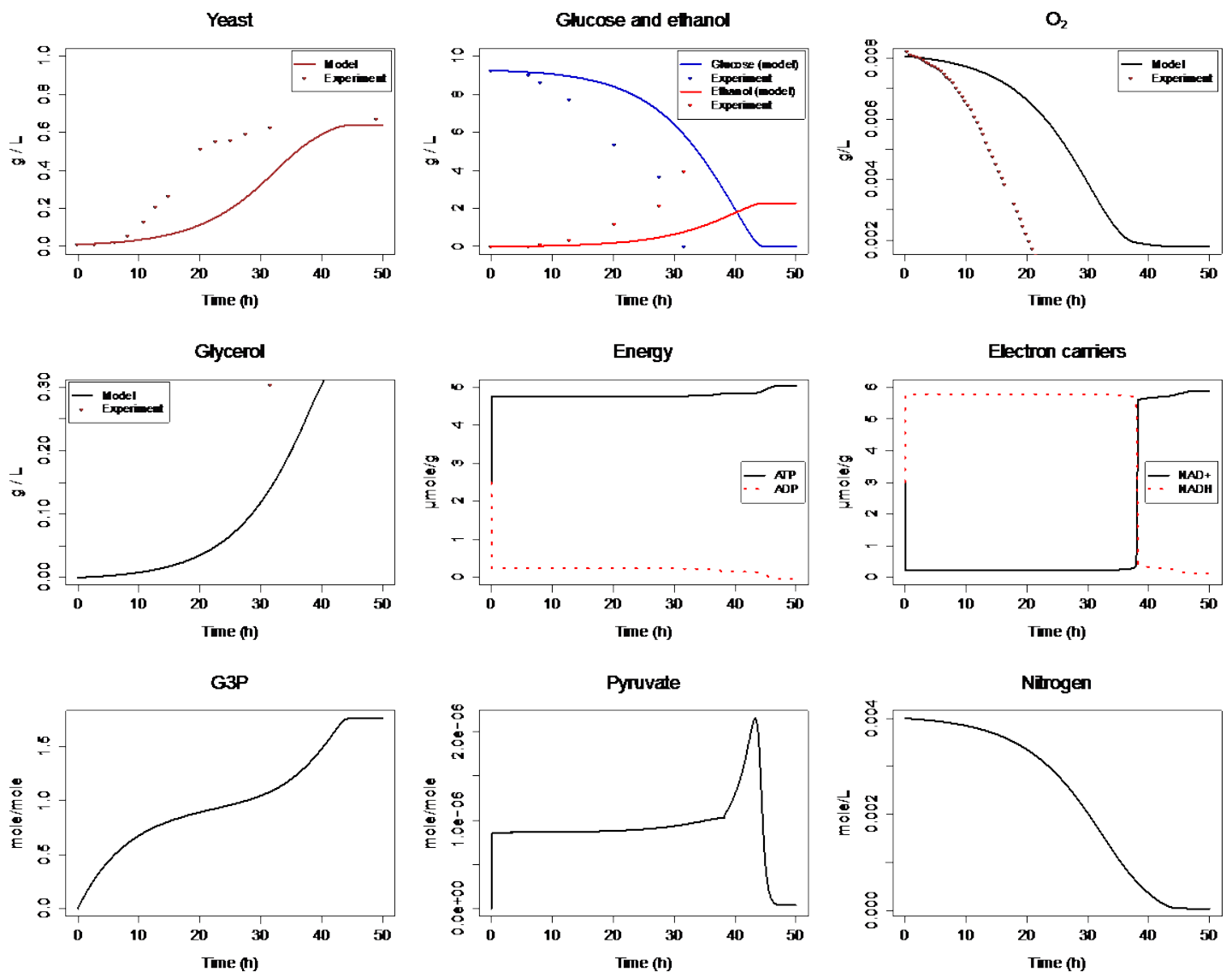

This article is protected by copyright. All rights reserved. 
Figure 5. Simulation results with a sink term of ATP to avoid ADP depletion. Comparison with experimental data.
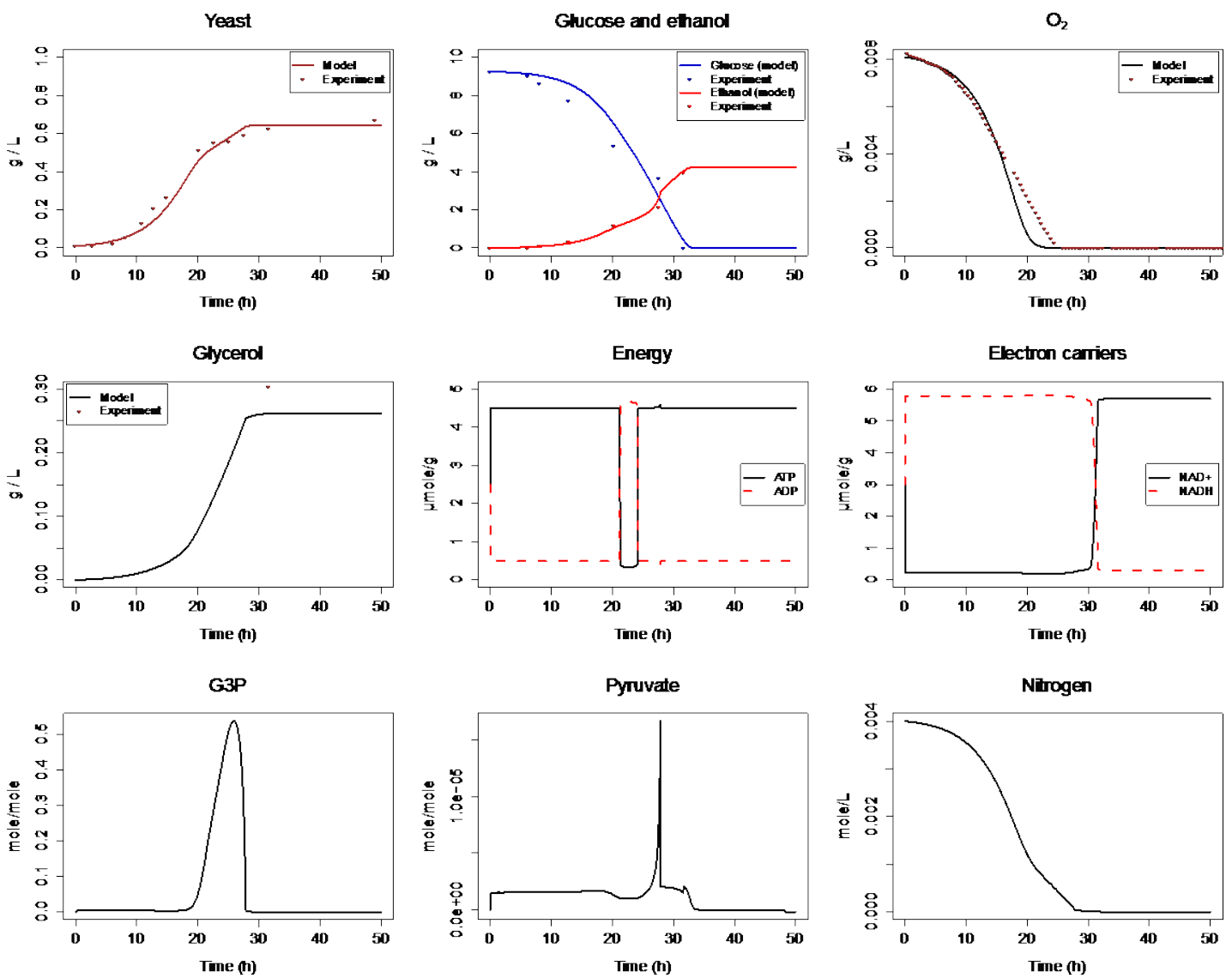

This article is protected by copyright. All rights reserved. 
Figure 6. Simulation results, without respiration: the yeast growth is dramatically reduced due to the lack of $\mathrm{NAD}^{+}$, which blocks the pyruvate pathway.
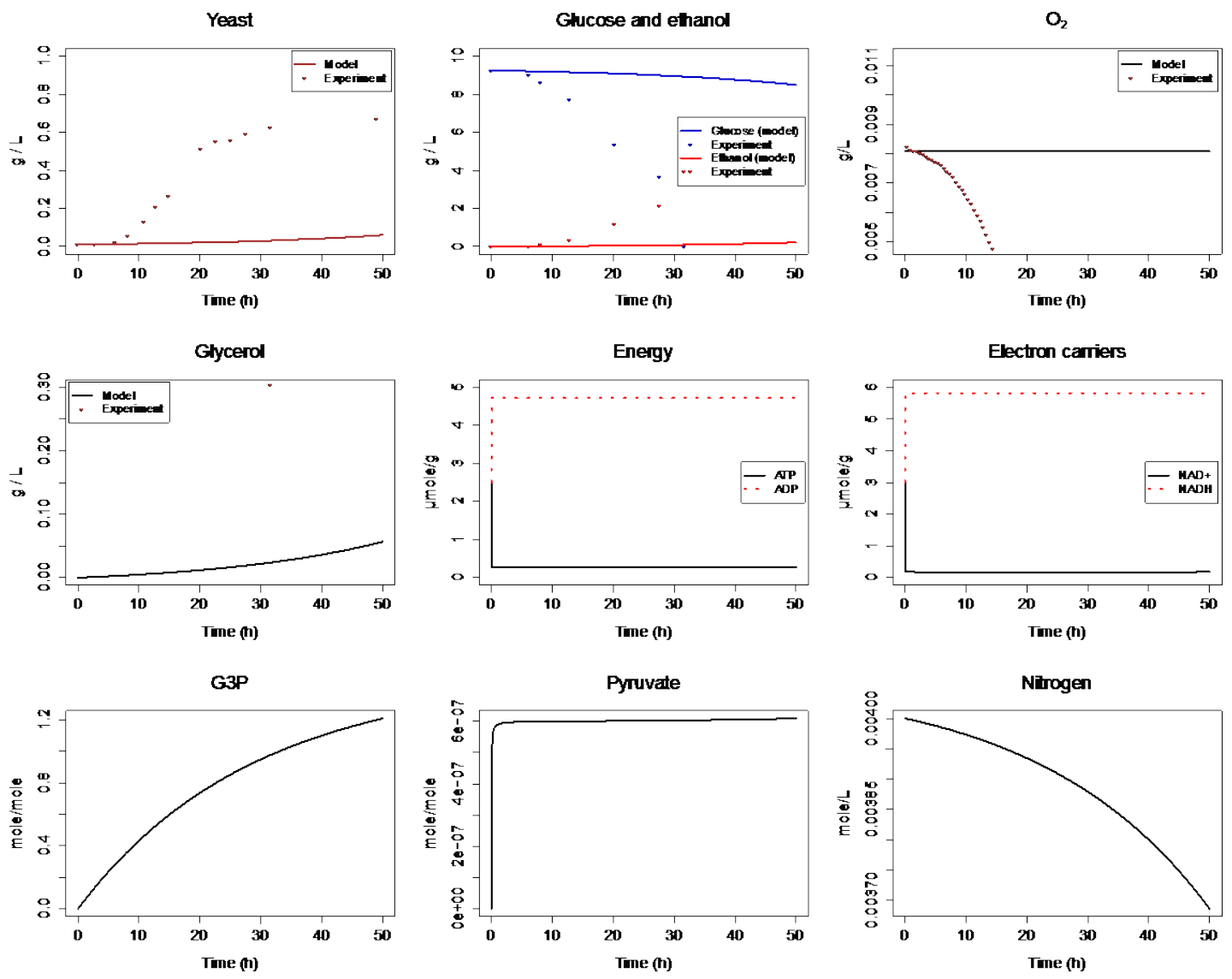

This article is protected by copyright. All rights reserved. 
Figure 7. Simulation results, without any limiting effects of NAD ${ }^{+}$. Comparison with experimental data. This simulation proves the ability of the electron carrier balance to trigger the glycerol pathway.
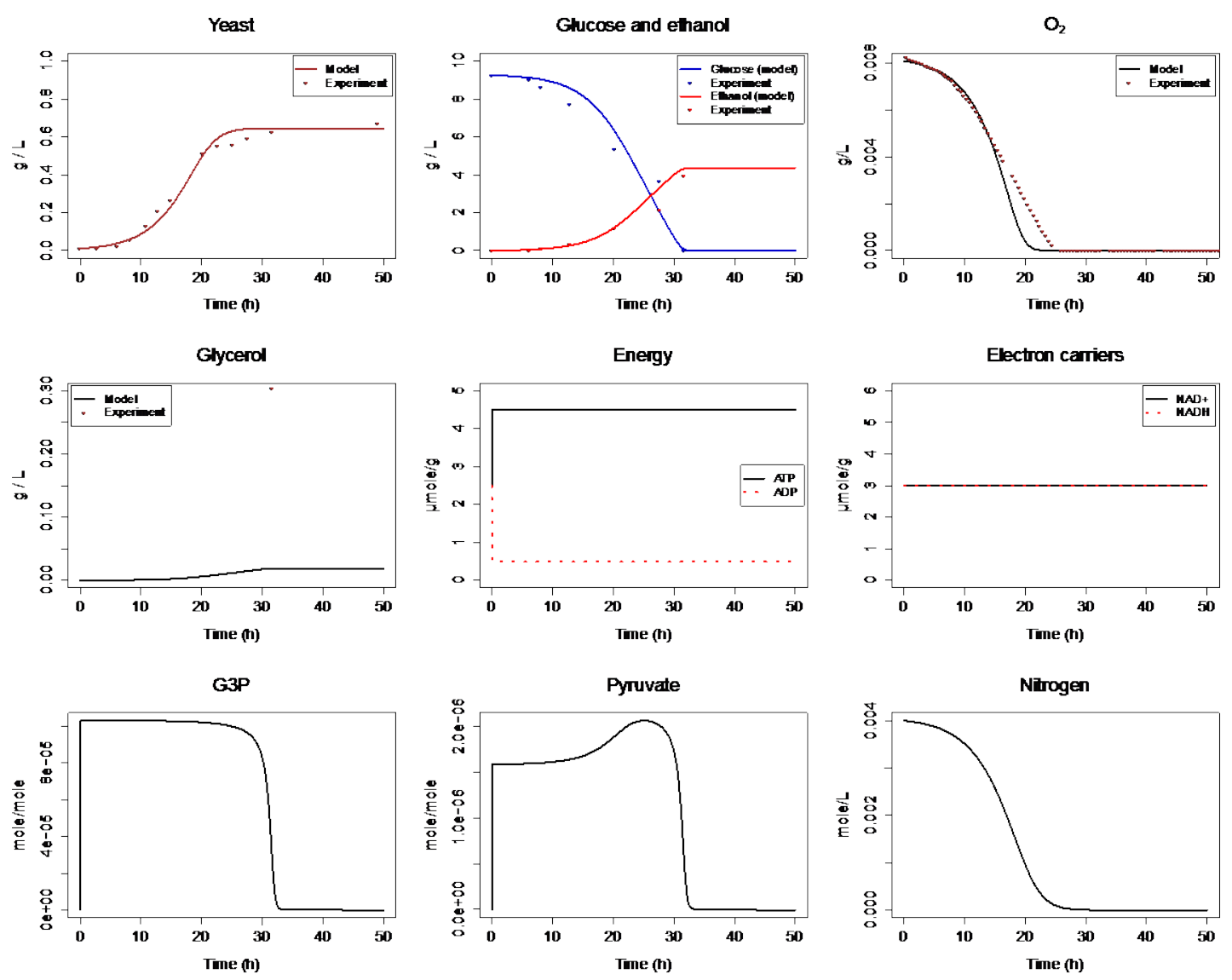

This article is protected by copyright. All rights reserved. 